\title{
Fresh Meat Selection for Consumers ${ }^{1}$
}

\section{Chad Carr, Ed Jennings, and Larry Eubanks ${ }^{2}$}

A solid working knowledge of fresh meat terminology will help consumers select meat cuts which will perform desirably in all recipes.

The three red meat species generally offered in U.S. retail markets are beef, pork, and lamb. The processing plant will slaughter the live animal to generate a carcass, with beef and pork carcasses being divided into sides. Carcasses are chilled to ensure food safety and quality. Almost all carcasses from meat animals are cut into wholesale cuts while at the initial slaughter plant (Figure 1). Most food service distributors and some retailers have the ability to further cut primal and subprimals into retail cuts. Large red meat processors, such as Tyson, Cargill, Smithfield, and National Beef, operate further processing facilities which create ready-to-sell packaged meats from subprimal cuts. This minimizes skilled-labor costs for large retailers, such as Wal-Mart and Target.

The biological role of the muscles that comprise these cuts makes a huge influence on the ultimate eating quality, or palatability, of the products. Muscles attached to the fore and/or hind limb are muscles of locomotion and these cuts tend to have more connective tissue and be more inconsistent in

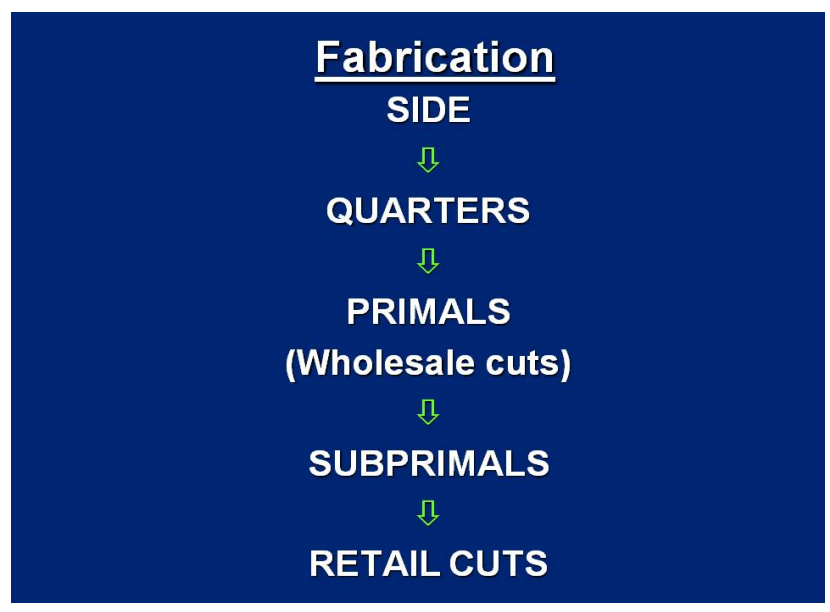

Figure 1. Flow diagram of red meat fabrication.

cooked product tenderness than cuts from muscles of posture, though exceptions between and within species certainly exist. Additionally, there is generally less variation in the eating quality of pork than beef and lamb. This is because there is less genetic and environmental variation in how modern U.S. market hogs are raised than fed cattle or lambs. Ultimately, the carcass pieces not utilized as whole-muscle cuts are used as lean trim for ground beef, pork, or lamb.

Consumers can do an excellent job selecting retail meat products, but still fail to maximize

1. This document is AN229, one of a series of the Animal Sciences Department, Florida Cooperative Extension Service, Institute of Food and Agricultural Sciences, University of Florida. Original publication date October 2009. Visit the EDIS Web Site at http://edis.ifas.ufl.edu.

2. Chad Carr, assistant professor, Department of Animal Sciences; Ed Jennings, extension agent, Sumter County FL; Larry Eubanks, coordinator of research programs, Department of Animal Science; Florida Cooperative Extension Service, Institute of Food and Agricultural Sciences, University of Florida, Gainesville, FL 32611.

The Institute of Food and Agricultural Sciences (IFAS) is an Equal Opportunity Institution authorized to provide research, educational information and other services only to individuals and institutions that function with non-discrimination with respect to race, creed, color, religion, age, disability, sex, sexual orientation, marital status, national origin, political opinions or affiliations. U.S. Department of Agriculture, Cooperative Extension Service, University of Florida, IFAS, Florida A. \& M. University Cooperative Extension Program, and Boards of County Commissioners Cooperating. Millie Ferrer-Chancy, Interim Dean 
palatability by improper preparation and cooking.

Cuts with less connective tissue can be prepared via dry heat, without added moisture. This would include grilling, roasting, broiling, and frying. Cuts with more connective tissue should be prepared using added moisture to help turn connective tissue into gelatin. Examples of moist heat include braising or cooking in liquid. Other options for cuts with more connective tissue include cooking for a long time at a low temperature via indirect heat, such as smoking.

The inside of muscle is naïve to any pathogens which can cause food-borne illness. However, pathogens such as Salmonella and E. coli O157:H7 often live within the digestive tract of meat animals and can be transferred to the carcass surface during slaughter (Gill, 1979). Therefore, it is essential that all ground beef, pork, or lamb be cooked to $160^{\circ} \mathrm{F}$, as checked by a properly calibrated cooking thermometer in the thickest part of the patty (Clavero et al., 1998).

The surface of whole-muscle cuts of meat, such as steak, chops, and roasts will reach $160^{\circ} \mathrm{F}$ during cooking, thus ensuring heat destruction of surface bacteria. Because the interior of these products have not been exposed to pathogens they are safe at a medium rare $\left(145^{\circ} \mathrm{F}\right)$ degree of doneness (Gill, 1979). The tenderness and juiciness of many whole-muscle products is maximized at this temperature (Parrish et al., 1973; Wulf et al., 1996).

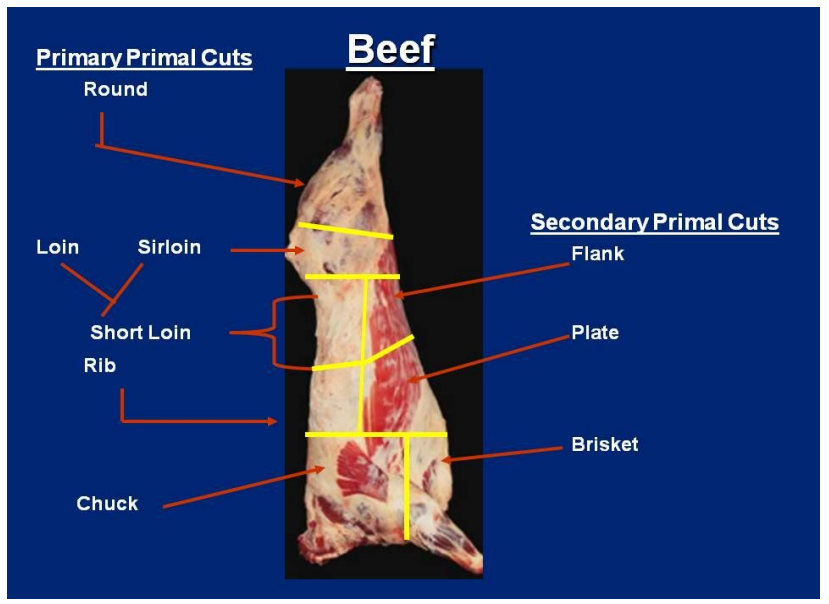

Figure 2. Diagram of beef primal cuts.

\section{Beef}

There are four primary and three secondary primal cuts which are typically generated from a beef carcass (Figure 2). The chuck and round are sometimes referred to as "end meats" and the loin and rib as "middle meats", both collectively referring to their location on the carcass. Traditionally, end meats have been utilized to generate roasts, lean trimmings, and some lower valued steak cuts.

Over the past 25 years, commercial beef processors have transitioned from fabricating mostly bone-in, to almost exclusively boneless beef products.

All cuts referenced are depicted by the chart available at http://www.beefretail.org/uDocs/ bmezretailcutchart.pdf

The chuck refers to the cuts generated from the shoulder (Figure 2). The two primary components of the chuck are the chuck roll and the clod, with the two preeminent cuts generated being a boneless arm roast and a boneless chuck roast. The round refers to the cuts generated from the hind leg (Figure 2). The primary components of the round are the inside round, bottom round, eye of round, and the knuckle (or sirloin tip), with roasts and some steaks being generated from all of these subprimals. Roasts from the round and chuck should incorporate moisture during cooking or should be cooked over indirect heat for an extended time to maximize palatability.

Due to highly variable tenderness, subprimals from the chuck and round are often enhanced. Enhancement is the process of injecting whole-muscles with a solution containing salt and phosphate. This is a well established process in beef and pork processing which decreases endpoint variability (Sheard and Tali, 2004), and improves consumer acceptability of cooked tenderness and juiciness (Baublits et al., 2006; Moeller et al., 2009). However, since the inside of an enhanced steak is no longer sterile, these steaks should be cooked to $150^{\circ} \mathrm{F}$ to ensure elimination of any potential pathogens (Gill et al., 2009).

Researchers from the University of Florida and the University of Nebraska recently profiled the 
muscles of the beef carcass and established fabrication methods to add value to these end meats (Von Seggern et al., 2005; Jones et al., 2005). The Beef Checkoff, National Cattlemen's Beef Association, and several university researchers have worked to establish several value-added steak cuts. Some of these steaks developed from the clod include: the flat iron and petite tender steaks; http://www.beefinnovationsgroup.com/ shoulderclod1.aspx; from the chuck roll: the Denver, Delmonico, and Sierra steaks; http://www.beefinnovationsgroup.com/ chuckroll1.aspx; and from the round: the Western griller, tip center, and tip side steaks.

\section{http://www.beefinnovationsgroup.com/} round.aspx. These steaks should be cooked using dry heat to a medium or medium rare degree of doneness. Even without enhancement, these steaks are moderately tender and highly palatable.

The rib and loin are separated between the last (13th) and 12th ribs, with the section closest to the round being the loin and the other the wholesale rib (Figure 2). Two subprimals are generated from the wholesale loin; the short loin and the sirloin.

The short loin is the one beef subprimal often left intact to generate T-bone and Porterhouse steaks. Alternatively, processors can elect to remove the bones to create strip and tenderloin steaks. The sirloin is divided into two sections the top sirloin butt and the bottom sirloin, which consists of the ball tip, tri tip and flap. The wholesale rib is generally fabricated into boneless ribeye steaks. Collectively, steaks from the rib and short loin exceed sirloin steaks for tenderness. Most all steaks from the loin and rib should have acceptable tenderness when cooked over dry, direct heat.

The remaining wholesale cuts (brisket, plate, flank) are less tender cuts that should be cooked over indirect heat for an extended time and/or with additional moisture to maximize palatability.

\section{Pork}

There are four lean cuts, two fatty cuts and one bony cut generated from a pork carcass (Figure 3 ). All cuts referenced are depicted by the chart available at

http://www.theotherwhitemeat.com/docs/ NotebookCutChart.pdf

Seventy-five percent of the pork carcass is further processed through curing, smoking, and/or enhancement (Cannon, 1995).

The ham comes from the hind leg and the belly, spareribs, and jowl from the side and neck, respectively (Figure 3). Essentially, all hams, bellies, and jowls are cured by adding sodium nitrite and smoked, prior to being made available at retail or foodservice as fully-cooked ham products or heat-treated bacon and jowl.

The intact shoulder generates two primal cuts, the Boston butt and picnic shoulder (Figure 3). The Boston butt can be cut into bone-in blade roasts and steaks or sold boneless. The picnic shoulder can be used to make thin cutlets, or roasts. The loin comes from the back of the pig, with the belly coming from the side. The loin extends all the way from the ham to the intact shoulder. The entire loin can be fabricated into bone-in blade, rib, loin, and sirloin chops and roasts, or boneless loins, tenderloins, and backribs.

Backribs and spareribs are both sold fresh and should be prepared similarly, by cooking over indirect heat for an extended time and/or with additional moisture to maximize palatability.

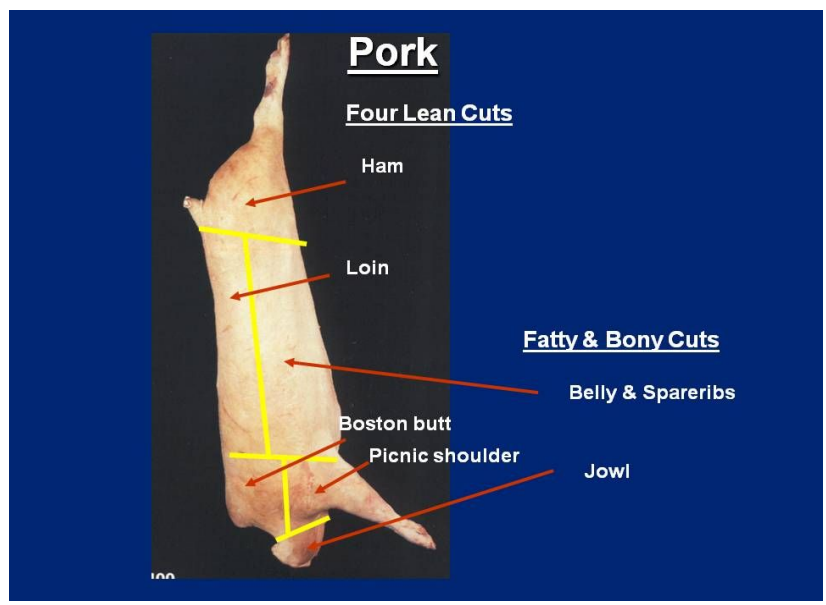

Figure 3. Diagram of pork primal cuts.

Researchers from the University of Wisconsin, Iowa State University, and Michigan State University recently profiled the muscles of the pork carcass and established fabrication methods to add value to 
underutilized cuts of the ham and picnic.

Accordingly, The National Pork Board has established several new cuts, primarily marketed toward foodservice.

http://www.theotherwhitemeat.com/hotnewcuts/ home.aspx. The cap steak

http://www.theotherwhitemeat.com/hotnewcuts/ capsteak.aspx and the pocket roast

http://www.theotherwhitemeat.com/hotnewcuts/ pocketroast.aspx both come from the wholesale ham and are byproduct trim of the manufacturing of boneless hams. The pork breast http://www.theotherwhitemeat.com/hotnewcuts/ porkbreast.aspx is a superficial muscle of the picnic shoulder which is easy to isolate. When these cuts are cooked over dry heat to a medium degree of doneness, they are moderately tender, and highly palatable pork entrees. All fresh pork cuts not from the loin should incorporate moisture during cooking or should be cooked over indirect heat for an extended time to maximize palatability.

\section{Lamb}

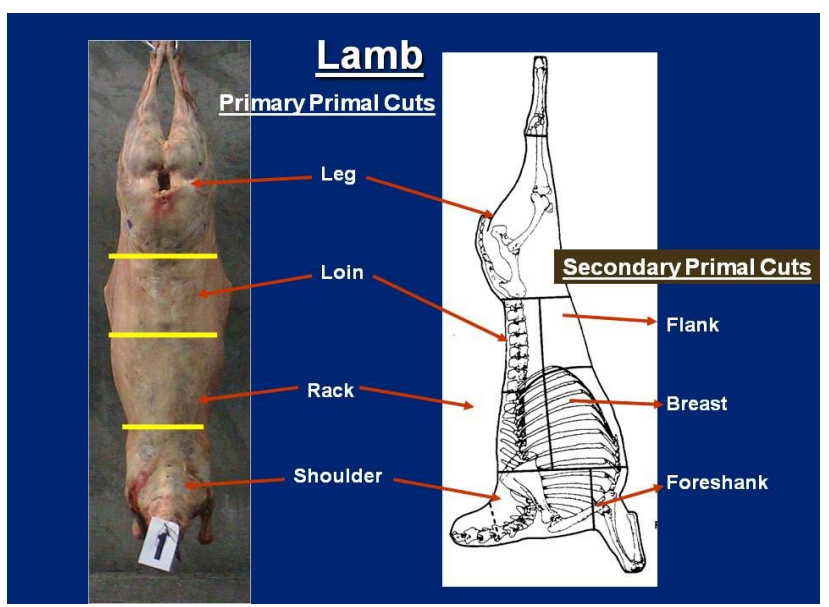

Figure 4. Diagram of lamb primal cuts.

There are four primary and three secondary primal cuts generated from a lamb carcass (Figure 4). All cuts referenced are depicted by the chart available at http://www.americanlamb.com/lamb101/cuts.aspx.

Almost all lamb cuts are sold bone-in. The rack and loin are separated between the last (13th) and 12 th ribs, with the section closest to the leg being the loin and the other the wholesale rack, with both primal cuts being fabricated into chops, respectively (Figure 4).
The leg includes both the sirloin and leg, which are separated and cut into bone-in or boneless roasts and chops. The square-cut shoulder is further divided into bone-in arm and blade chops or roasts. Cuts from the rack and loin can be cooked over dry, direct heat. Cuts from the shoulder and leg should be cooked over indirect heat for an extended time.

Cuts from the breast, foreshank, and flank have more connective tissue than the four primary cuts and should be prepared over indirect heat for an extended time and/or with additional moisture to maximize palatability.

\section{Conclusion}

Educating consumers about how to prepare safe and delicious meals with animal foods will improve the palatability of red meat products prepared and consumed in the home, and ultimately will help to increase domestic red meat consumption.

\section{Literature Cited}

Baublits, R. T. , J. F. Meullenet J. T. Sawyer, J. M. Mehaffey, and A. Saha. 2006 . Pump rate and cooked temperature effects on pork loin instrumental, sensory descriptive and consumer-rated characteristics. Meat Sci. 72 : $741-750$.

Cannon, J. E., J. B. Morgan, F. K. McKeith, G. C. Smith, and D. L. Meeker. 1995. Pork quality audit: A review of the factors influencing pork quality. J. Muscle Foods. 6: 369-402.

Clavero, M. R. S., L. R. Beuchat, and M. P. Doyle. 1998. Thermal inactivation of Escherichia coli $\mathrm{O} 157: \mathrm{H} 7$ isolated from ground beef and bovine feces, and suitability of media for enumeration. J. Food Protection. 61:285-289.

Gill, C. O. 1979. Intrinsic bacteria in meat. Journal of Applied Bacteriology, 47, 367-378.

Gill, C.O., L. F. Moza, and S. Barbut. 2009. Survival of bacteria in less than thorough cooked, brine-injected steaks. Food Control 20: 501-507. 
Jones, S. J., C. R. Calkins, D. D. Johnson, and B. L. Gwartney. 2005. Bovine myology. Lincoln, NE: University of Nebraska.

Available:http://bovine.unl.edu .

Moeller, S.J., R.K. Miller, K.K., Edwards, H.N. Zerby, K.E. Logan, T.L. Aldredge, C.A. Stahl, M. Boggess, and J.M. Box-Steffensmeier. 2009.

Consumer perceptions of pork Meat Sci: In Press.

Parrish, F. C., D. G. Olson, B. E. Miner, and R. E. Rust. 1973. Effect of degree of marbling and internal temperature of doneness on beef rib steaks. J. Anim. Sci. 37:430-434.

Sheard, P. R. and A. Tali. 2004. Injection of salt, tripolyphosphate and bicarbonate marinade solutions to improve the yield and tenderness of cooked pork loin. Meat Sci. 68: 305-311.

Von Seggern, D. D., C. R. Calkins, D. D. Johnson, J. E. Brickler, and B. L. Gwartney. 2005. Muscle profiling: Characterizing the muscles of the beef chuck and round. Meat Sci. 71:39-51

Wulf, D.M., J. B. Morgan, J. D. Tatum, and G. C. Smith. 1996. Effects of animal age, marbling score, calpastatin activity, subprimal cut, calcium injection, and degree of doneness on the palatability of steaks from Limousin steers. J. Anim. Sci. 74:569-576. 